\title{
Assessing residual hydropower potential of the La Plata Basin accounting for future user demands
}

\author{
I. Popescu ${ }^{1}$, L. Brandimarte ${ }^{1}$, M. S. U. Perera ${ }^{1}$, and M. Peviani ${ }^{2}$ \\ ${ }^{1}$ UNESCO-IHE Institute for Water Education, Delft, The Netherlands \\ ${ }^{2}$ RSE S.p.a. Research on Energy System, Seriate, Italy
}

Correspondence to: I. Popescu (i.popescu@ unesco-ihe.org)

Received: 23 March 2012 - Published in Hydrol. Earth Syst. Sci. Discuss.: 27 April 2012

Revised: 11 July 2012 - Accepted: 27 July 2012 - Published: 17 August 2012

\begin{abstract}
La Plata Basin is shared by five countries (Argentina, Bolivia, Brazil, Paraguay and Uruguay), which have fast growing economies in South America. These countries need energy for their sustainable development; hence, hydropower can play a very important role as a renewable clean source of energy. This paper presents an analysis of the current hydropower production and electricity demand in $\mathrm{La}$ Plata Basin (LPB), and it analyses the maximum and residual hydropower potential of the basin for a horizon of $30 \mathrm{yr}$ (i.e. year 2040). Current hydropower production is estimated based on historical available data, while future energy production is deduced from the available water in the catchment (estimated based on measured hydrographs of the past years), whereas electricity demand is assessed by correlating existing electricity demand with the estimated population growth and economic development. The maximum and residual hydropower potential of the basin were assessed for the mean annual flows of the present hydrological regime (1970-2000) and topographical characteristics of the area.

Computations were performed using an integrated GIS environment called VAPIDRO-ASTE released by the Research on Energy System (Italy). The residual hydropower potential of the basin is computed considering first that the water supply needs for population, industry and agriculture are served, and then hydropower energy is produced. The calculated hydropower production is found to be approximately half of the estimated electricity demand, which shows that there is a need to look for other sources of energy in the future.
\end{abstract}

\section{Introduction}

Energy produced by hydropower has several advantages over fossil fuels (coal, petroleum, natural gas) and nuclear power (uranium): it is renewable; it has low pollution impact on the environment; it reduces the greenhouse gas emissions; it implies relatively low maintenance; it is reliable in terms of technology and it is proven over time.

Hydropower plays a vital role in more than 150 countries over the globe; according to the statistics of the International Journal on Hydropower and Dams, hydropower contributes at least $90 \%$ of the electricity production in 23 countries and at least $50 \%$ in 63 countries (IHA/IEA/CHA, 2000). The world's gross theoretical hydropower potential is about $40000 \mathrm{TWh}$, of which $14000 \mathrm{TWh}$ could be used as the technical feasible hydropower potential. At present $7000 \mathrm{TWh}$ are used as economically feasible hydropower potential. Most of the unexploited economically feasible hydropower potential lies in emerging countries or countries in transition (Yuksel, 2010). Even though the contribution of hydropower to the socio-economic development process could be valuable, it is still low when compared with the contribution of overall energy mix of the world. This is estimated as low as $6.15 \%$ of the total energy mix of the world (Dudhani et al., 2006). It is expected that the remaining hydropower potential of the world would not supply the total future electricity demand, but it is needed to harness the remaining hydropower potential to meet the increasing electricity demand as a clean renewable source of energy (Dudhani et al., 2006).

Nowadays, worldwide, many studies are carried out to identify the hydropower potential and to promote 
hydropower projects in large- and small-scale basins. Kosnik $(2008,2010)$ studied the potential for small-scale hydropower to contribute to the United States of America (USA) renewable energy supplies, and identified several thousands of viable sites for the hydropower production throughout the USA and showed that cost effectiveness is an important factor in developing these sites. It was revealed that the average cost for developing small-scale hydropower sites is relatively high; however, there are hundreds of sites that can be implemented at the lower side of the cost scale.

Supriyasilp et al. (2009) studied the use of multi-criteria decision making (MCDM) to determine the priority of hydropower projects, over $100 \mathrm{KW}$, in the Ping River Basin in Thailand. Their assessment of the advantages and disadvantages of 64 projects was based on five criteria: electric generation, engineering and economics, socio-economics, environment, and stake holder involvement. The weights for the criteria were given by two groups of experts who identified the environment as the most important aspect among the five criteria, followed by socio economics, electricity generation, engineering and economics and stake holder involvement. This study also shows the importance of including nontechnical aspects when ranking priorities for the selection of sites for hydropower development.

Ohunakin et al. (2011) evaluated hydropower development with respect to the established policies and energy power sector reform in Nigeria. Authors highlighted the urgency for incorporation of subsides, feed-in tariffs, and framework for Price Purchase Agreements (PPA) into the small-scale hydropower agreements in order to promote the small hydropower projects and to attract local and foreign investors.

China has the highest gross amount of water resources, and by the end of 2010 reached 852 million $\mathrm{kW}$, due to the need to supply the increasing energy demand and to minimize the environmental pollution to achieve the sustainable development (Chang et al., 2010).

The study of the current role of the hydropower production, remaining potential and some development plans related to hydropower in various parts of the world reveals that South America is one of the regions that has vast unexploited hydropower potential and there will be major hydropower developments, in the future, in countries such as Brazil (28 600 MW), Bolivia (700 MW), Paraguay and Argentina (2000 MW) (Qurios, 2002; Clarke, 2007).

Modern techniques such as geographic information system (GIS) and remote sensing (RS) are widely used nowadays for the assessment of hydropower potential (Conolly et al., 2010). The main reasons for the use of GIS and RS are the free availability of some GIS software and digital elevation models (DEM), easy extraction of data such as river networks, topographic information, land use, etc, and presentation of outputs in graphical format which can be understood nowadays also by non-experts (Gichamo et al., 2012; Hartanto et al., 2011).
Such modern techniques were applied for example in Bangladesh and reported by Mondal and Denich (2010) in their assessment of the potential of different renewable sources (solar, hydro, wind power). Dudhani et al. (2006) proposed a method to identify probable sites for small-scale hydropower generation in mountain areas of India, based on the use of remote sensing data. The algorithm was developed in Visual Basic platform for the identification and assessment of water resources in plain and mountain areas and was applied for the IRS-ID, LISS III Geo-coded False Color Composite satellite images.

Alterach et al. (2008) developed a GIS integrated tool, the VAPIDRO-ASTE, which can be used to determine the hydropower potential maps for Italy for nearly 1500 interconnected sub-basins at national scale with known hydrological and physiographic characteristics.

Hydropower generation is not new to La Plata Basin (LPB). There are more than 30 large hydropower plants, such as the following: Itaipu (12600 MW), Ilha Solteira (3444 MW), Salto Santiago (2000 MW), Itumbiara (2200 MW), São Simão (1710 MW), Porto Pimavera (1814 MW), Ita (1450 MW), Jupiá (1411 MW) etc., which provide most of the hydroelectricity for the region. Some of the large hydropower plants such as Itaipu (12600 MW, Brazil and Paraguay), Salto Grande (1890 MW, Argentina and Uruguay) and Yacyretá (3100 MW, Argentina and Paraguay) were built on bilateral agreements between countries to share the power production (WWAP-UNESCO, 2007).

The countries in the LPB are highly dependent on hydroelectricity (Barros et al., 2008): $76 \%$ of the total installed capacity of power in the countries of LPB, in the year 2000, was provided by hydropower. LPB is endowed with $28 \%$ of world's water resources. This, along with its topographical distribution, contributes to the high hydropower potential that can be utilized for the increasing electricity demand due to growth of population and economic development of the five LPB countries.

However, the present hydropower production is exposed to stream flow variations due to climatic variability in the region. In addition to climatic variability, hydropower production has been limited by water withdrawals operated by different users such as agricultural, municipal and industrial sectors. The number of water withdrawals is increasing with the growing population, urbanization, land use changes (e.g. due to construction of large reservoirs), changes of cropping pattern, agricultural, industrial and infrastructure development (OSA, 2005).

The World Water Assessment Programme of the United Nations (WWAP-UNESCO, 2007) favours the development of both renewable (hydropower) and non-renewable (petroleum) sources to achieve the goals and strategies for future energy demand. However, it highlights the importance of development of hydropower in LPB as the limited resource availability of non-renewable sources. 
The Organization of American States (OSA, 2005) has identified that LPB has high hydropower potential due to basin characteristics and discharges. To exploit the remaining hydro potential of the basin, it is necessary to carry out a proper assessment of remaining potential. The advent of modern computation tools, such as geographical information system (GIS), remote sensing and hydrological models, can support us in making accurate estimation of river flows and water availability in a particular section of a river (Gichamo et al., 2012). Based on these flow computations, the estimation of the hydropower potential is improved as well.

The maximum hydropower potential of a watershed is the possible hydropower production if the natural available hydrological profile and the topographic watershed configuration are taken into account. The residual potential hydropower expresses the watershed potential taking into account the flow withdrawal schemes and the minimum instream flow constrains.

This paper presents an analysis of the current hydropower production and electricity demand in La Plata Basin (LPB), and it analyses the maximum and residual hydropower potential of the basin for a $30 \mathrm{yr}$ horizon (i.e. year 2040). Current hydropower production is estimated based on historical available data, while future energy production is deduced from the available water in the catchment (estimated based on measured hydrographs of the past years), whereas electricity demand is assessed by correlating existing electricity demand with the estimated population growth and economic development. The maximum and residual hydropower potential of the basin are assessed for the mean annual flows of the present hydrological regime (1970-2010) and topographical characteristics of the area.

\section{Theoretical considerations on the assessment of the hydropower potential}

Hydropower is an important source of energy, especially in the countries of South American continent, where water available for hydropower production is abundant. Assessment of the hydropower potential, especially of the residual one, is an important tool for a proper plan of the energy use. This study assessed the potential hydropower energy production in La Plata Basin, in order to determine the residual hydropower potential in the basin.

In order to assess the potential hydropower, an analysis of the past hydrological regime in the catchment, for the last $70 \mathrm{yr}$, was made. Based on the hydrological regime in the catchment and on the physical characteristics of it, the potential hydropower of the basin was assessed by means of the GIS-based tools VAPIDRO-ASTE. Finally, future energy demand in the basin was estimated by regression analysis on the historical data.

VAPIDRO-ASTE is a GIS-integrated numerical tool (the software is developed in Visual Basic language and integrated with ARCGIS9) that allows the evaluation of the residual potential hydropower energy and all possible alternatives concerning the sites for hydroelectric plants along the drainage network, taking into account the relationship between the full costs of the hydropower and the benefits from selling the generated power in the national market. The tool takes into account the current water resources exploitation with its geographical location and elevation (with respect to irrigation uses, drinkable water, existing hydropower plants, etc.) and the limitation that this creates regarding the potentiality for energy production. Based upon a user-friendly graphical interface, the tool is able to split the river into hundreds of cross sections and to calculate the available discharges and potential hydropower production, considering constrains like minimum flow, withdrawals and restitutions scheme.

A brief overview of the equations applied to compute maximum potential and residual hydropower is outlined here. For a comprehensive description of the methods applied by VAPIDRO-ASTE to compute maximum potential and residual hydropower, the reader is invited to check Alterach et al. (2008).

The maximum potential hydropower establishes the theoretical top of energy that the study basin can produce assuming that all water resources are used to produce energy, which in real life application does not occur because of environmental flows, other water uses and economic cost/benefit analysis.

The potential hydropower at a given point of the river basin, with respect to the basin outlet section, has been computed with the following equation:

$$
\begin{aligned}
E_{\text {own_max }_{i}} & =\text { Conv } \times g \times \eta \times\left(A_{i} \times p_{i} \times \operatorname{cd}_{i}\right)\left(H_{i}-H_{\text {closure }}\right) \\
& =\text { Conv } \times g \times \eta \times Q_{i} \times\left(H_{i}-H_{\text {closure }}\right)
\end{aligned}
$$

where "Conv" is a unit conversion factor to calculate energy in $\mathrm{GWh} \mathrm{yr}^{-1}$ (Conv =0.00876); $g$ is the gravity constant; $\eta$ is the overall electrical efficiency, which depends on kind of turbine, generator, transformers and/or electrical transmission, water conductors, etc; $Q_{i}$ is the basin discharge and $H_{i}$ is the elevation of the given elementary area $i$; and $H_{\text {closure }}$ is the elevation at closure point. $Q_{i}$ is the product of $A_{i}$, elementary area $i ; p_{i}$-precipitation over the elementary area $i$ and $\mathrm{cd}_{i}$, and the rainfall-runoff coefficient of the elementary area $i$.

Thus, the potential of the entire watershed is given as the sum of the contributions of the $N$ elementary areas that create the river basin itself:

$E_{\text {own_max }}=\operatorname{Conv} \times g \times \eta \times \sum_{i}^{N}\left[\left(A_{i} \times p_{i} \times \operatorname{cd}_{i}\right)\left(H_{i}-H_{\text {closure }}\right)\right]$

If the river basin is seen as a physical entity, as a first approximation, it can be assumed that each basin has a unique constant precipitation $(p)$ and runoff coefficient (cd), uniformly distributed in the elementary areas. This means then that $p_{i}=p=$ constant and $\mathrm{cd}_{i}=\mathrm{cd}=$ constant. 
The above Eq. (2) can then be expressed in terms of mean watershed elevation:

$E_{\text {own_max }}=\operatorname{Conv} \times g \times \eta \times Q \times\left(H_{\text {mean }}-H_{\text {closure }}\right)$.

The residual annual potential hydropower related to a given watershed ( $\left.E_{\text {own_res }}\right)$, without considering upstream flow contributions, can be calculated, accounting for the minimum instream flow ( $\left.E_{\text {own_mif }}\right)$ and the actual withdrawals $\left(E_{\text {prel }}\right)$ as follows:

$E_{\text {own_res }}=E_{\text {own_mif }}-E_{\text {prel }}$,

where

$E_{\text {own_mif }}=\operatorname{Conv} \times g \times \eta \times\left(Q-\mathrm{MIF}_{\text {aff }}\right) \times\left(H_{\text {mean }}-H_{\text {closure }}\right)$

$E_{\text {prel }}-\operatorname{Conv} \times g \times \eta \times \sum_{j}^{n}\left[q_{j} \times\left(h_{j}-H_{\text {closure }}\right)\right]$,

where $\mathrm{MIF}_{\text {aff }}$ is the minimum instream flow and is computed as $10 \%$ of the $Q$, according to VAPIDRO's user manual; and $q_{j}$ represents the mean annual withdrawals from the given watershed (+ positive ) or the restored flows to the given watershed (- negative) at a particular point $j$, and $h_{j}$ is the elevation over sea level of the $j$ sections where the flows are taken or restored. Points $j$ are located along the river network. At a $j$ point, several watersheds $(i)$ could convene.

All the above formulas are expressed in International Metric System, i.e. S.I.

\section{Study area, data collection and analysis}

\subsection{Study area}

La Plata Basin (LPB) is the second largest river basin in South America and the fifth largest in the world with a drainage area over 3.1 million $\mathrm{km}^{2}$. Five countries - Argentina, Uruguay, Paraguay, Brazil and Bolivia - develop their daily activities within the basin borders (Fig. 1). It has been estimated by Barros et al. (2008) that almost $70 \%$ of the total Gross Domestic Product (GDP) of Argentina, Paraguay, Uruguay, Brazil and Bolivia is produced within the basin.

LPB has three main sub-basins: Paraná, Paraguay and Uruguay basins. The Paraná Basin is the largest of the three sub-basins, in terms of drainage area, and constitutes $48.7 \%$ of the overall area of the basin followed by Paraguay and Uruguay with $35.3 \%$ and $11.8 \%$ respectively. The Paraná River flows $4000 \mathrm{~km}$ from its source in Precambrian Brazilian Shield to its mouth in the Pampa Plain. The Paraguay River extends $2670 \mathrm{~km}$ southward from its sources in the western hills of the Brazilian shield to its confluence with the Paraná River, and the Uruguay River flows $1800 \mathrm{~km}$ from its source from the southern Brazil up to the Plata River. The Third World Water Assessment Programme of United Nations - WWAP - (WWAP-UNESCO, 2007) estimated that

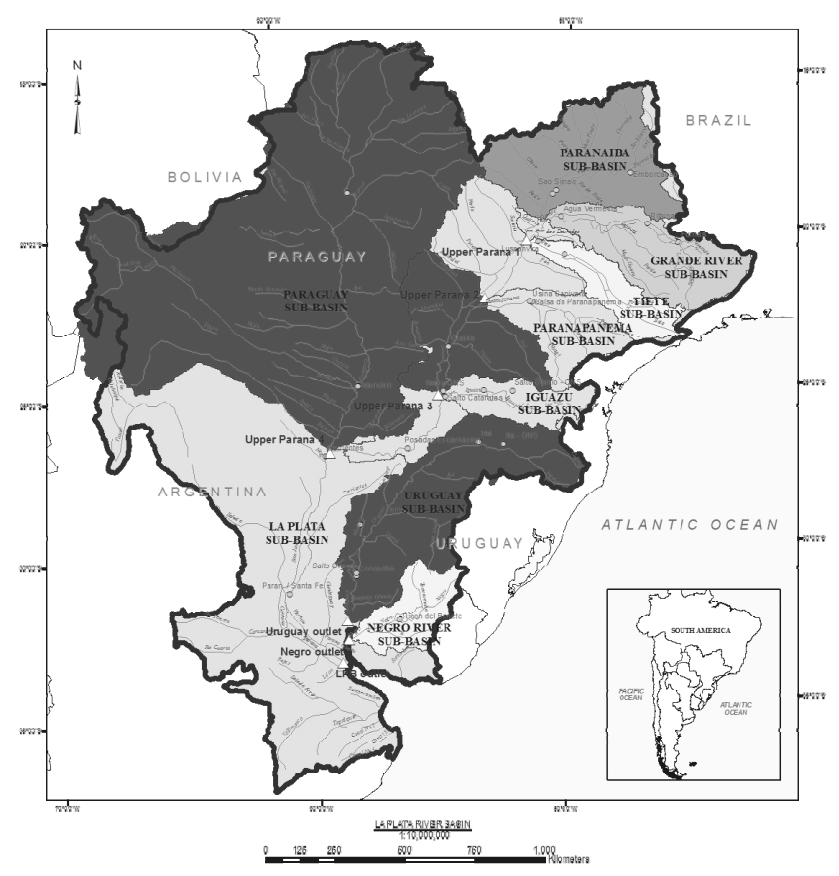

Fig. 1. La Plata Basin.

the population living in La Plata Basin was over 100 million inhabitants in early 2000 (WWAP-UNESCO, 2007). This represents more than $50 \%$ of the total population of the five countries together.

\subsection{Data collection and analysis}

In order to determine the maximum and residual potential of the LPB, different types of data were considered, such as hydrological data, population and population growth, land use practices, based on present land use and predicted growth of population and economic industrial growth of the region. We do acknowledge that land use and economic growth might not be exactly as we have estimated it. However, the method of estimating them based on population growth is the most logical to be used, in case that no other methods are in place to make such estimations.

Natural stream water availability in the LPB was determined from stream flow time series data of 38 gauging stations, located throughout the LPB (Fig. 2). Daily mean discharge, for a span of $80 \mathrm{yr}$ (1930-2010), was available for analysis. Figure 3 shows the data recorded at stream gauge 2, for 1932-2008. In the same figure, the dry, wet and mean hydrological years are highlighted.

Standard deviation and Tukey's boxplot methods were used to check and filter the outliers in the data.

Long time series data availability of discharge, observed at hydrometric stations in LPB, highlights the need of checking for inhomogeneities, which could be caused by changes in measurement procedures and techniques or even relocation 


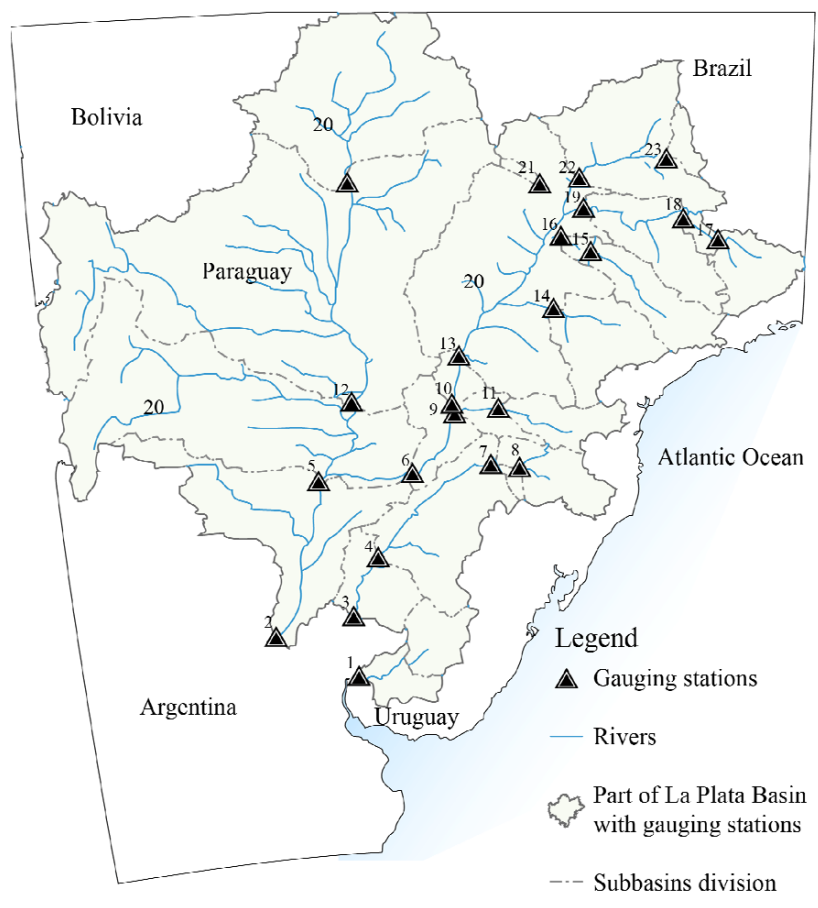

Fig. 2. Location of gauging stations in La Plata Basin.

of the observation stations. There are numerous statistical methods available to evaluate the homogeneity of monthly and/or annual climatic time series. The three most used test methods to determine the start of homogeneity in a set of time series are the standard normal homogeneity test (SNHT) for a single break (Alexandersson, 1986), the Buishand range test (Buishand, 1982) and the Pettitt test (Pettitt, 1979). All the above-mentioned tests assume under the null hypothesis that the annual values $Y_{i}$ of the testing variable $Y$ are independent and identically distributed, and a step-wise shift in the mean (a break) is present. These three tests are capable of locating the year where a break is likely to appear. All these three tests were applied in LPB, because although all three have many characteristics in common, they have different advantages as well. The SNHT detects breaks near the beginning and the end of a series, whereas the Buishand range and the Pettitt test are more sensitive to breaks in the middle of a time series (Hawkins, 1977). In the SNHT and the Buishand test, $\mathrm{Y}_{i}$-values are assumed to be normally distributed, while in the Pettitt test this assumption is not necessary.

After the elimination of the outliers in the data, all three homogeneity tests consistently showed that there is a change point in the stream flow time series, around the year 1970 in most of the stream flow series in LPB (Fig. 4). It is clearly seen that the mean annual flow of the years prior to 1970 is higher than the mean annual flow of the time series after 1970s. Nineteen stations in the LPB catchment are shown in Fig. 5, for exemplification of this phenomenon. The explanation for this change in the hydrological regime of the

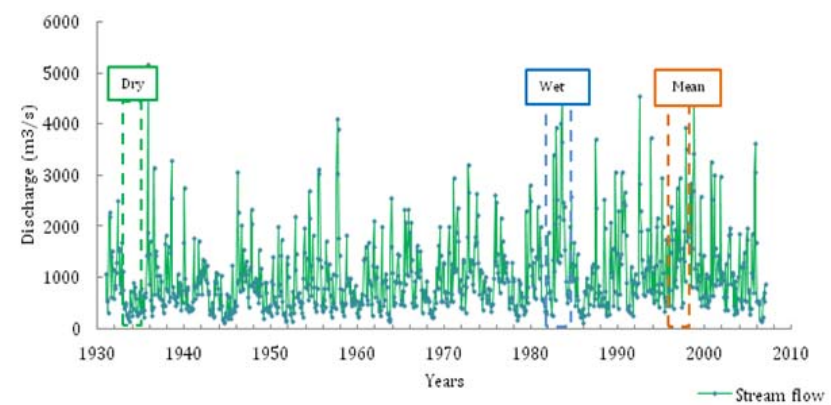

Fig. 3. Hydrological regime in La Plata Basin, recorded at stream gauge 2 (1932-2008). Wet, dry and mean hydrological years are highlighted in the series.

catchment is due to the variation of land use pattern and deforestation after 1950s in LPB (Mondal and Denich, 2011; Bartle, 2002; Collichsonn et al., 2001), as well as the changes in the rainfall regime in the area (Barros et al., 2008). Barros et al. (2008) points out that, during the 1970s, intense deforestation took place in the LPB, giving room for agriculture. These changes have contributed to the change in evapotranspiration and surface runoff, which increased the mean annual flow. Flow measurements on the Paraná River in the downstream part of the LPB are confirming these changes. This study focuses on the close horizon, year 2040. Therefore, the last $40 \mathrm{yr}$ of data are representative for the study.

Results of homogeneity test, for the stream flow data of a gauge station in the catchment (at the S. Osorio ONS gauge station), for the standard homogeneity test results shown in Fig. 4. Figure 5 shows the mean annual averages of the two considered interval of time series, 1931-1970 and 19712006, for 19 gauging locations in LPB.

This analysis pointed out that only the last $40 \mathrm{yr}$ of data should be used for the study and for prediction of the potential hydropower availability in the basin.

Population data in the LPB were gathered from the published census of the LPB countries (INDEC, 2011), as well as data for the GDP (FAOSTAT, 2011). Data on land use, in year 2010, were downloaded from http://www.fao.org (FAOSTAT, 2011).

\section{Assessment of LPB maximum and residual potential hydropower}

As mentioned above, the hydropower potential for the current LPB situation was done using the VAPIDRO-ASTE tool for today's available data, while the estimation for the year 2040 was done after all water uses were extracted from the available water. This section presents how the water uses for the year 2040 were estimated, and the estimation of hydropower for 2010 and 2040. 


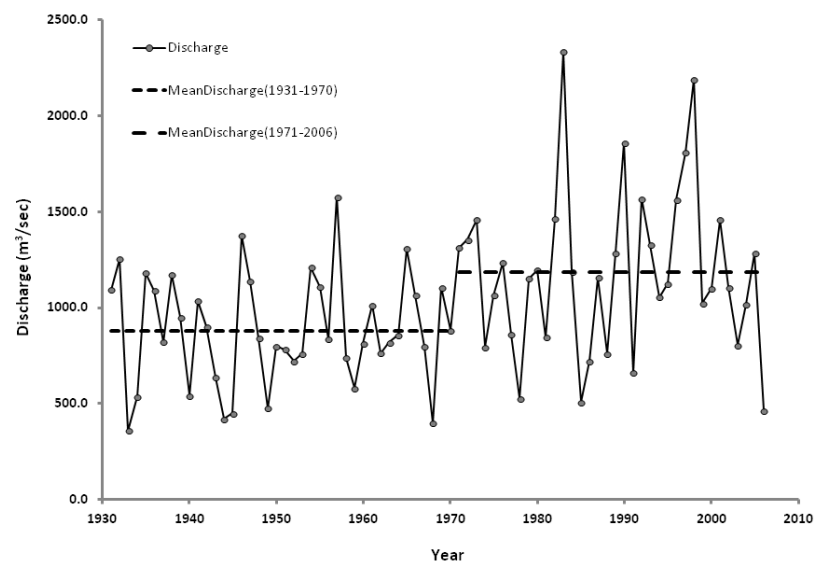

Fig. 4. Standard homogeneity test result for data series from 19312006 at gauge station 2.

The main water uses in a basin, in general, are agricultural, municipal and/or industrial. Growth in water usage for these three categories is driven by the population and its growth.

\subsection{LPB Population growth analysis}

From the census of the years 1980 up to 2010, the population growth of LPB and its estimation for the year 2040 were analyzed using exponential (Eq. 7) and logistic (Eq. 8) growth models:

$P(t)=P_{o} e^{k t}$

$P(t)=\frac{k P_{o}}{\left(k-b P_{o}\right) e^{-k t}+b P_{o}}$

where $k$ and $b$ are coefficients determined from the trends of growth of existing census data, $t$ is time and $P_{o}$ is the population at start year of the computation (i.e. 2010).

Population growth models depend on the trend of population growth. According to population growth studies (Carlson, 1913), population growth should be modelled in two ways depending on the population size at a certain moment in time. The exponential growth model depicts a rapid growth of population, whereas the logistic growth of population depicts a saturation of population in time. This is strongly correlated with the resources and change of culture of a country. As population grows, economy is expected to grow, and the living standard will grow. As soon as the living standard grows, the population growth starts to follow the logistic trend. In LPB the census data were available for each country, till year 2010. In order to identify which of the models are applicable for each country, both models were applied to the collected population data. After determining the population growth model of each LPB country, the estimation of the expected population in 2040 could be determined.

The growth of population in Argentina, Bolivia, Brazil, Paraguay and Uruguay was computed based on the census available up to the year 2000 and the prediction of the

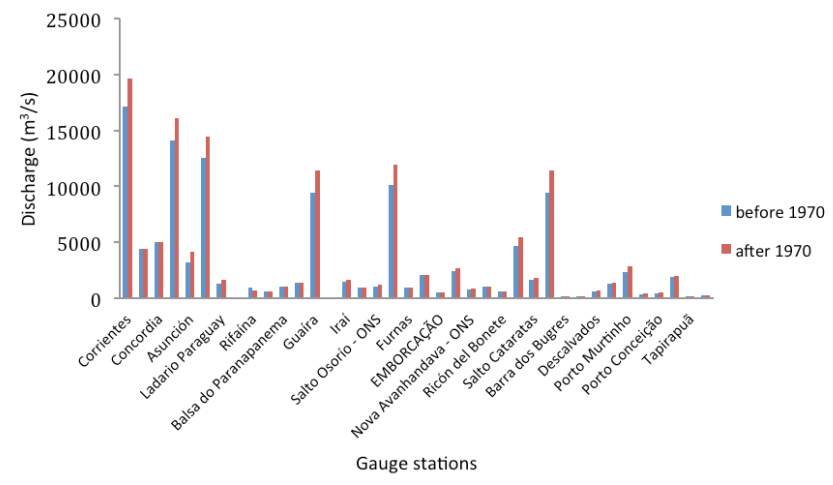

Fig. 5. Mean annual stream flows of the two time series intervals: 1931-1970 and 1971-2006.

population according to the logistic (L) and exponential (E) growth model, after year 2010 until year 2040.

According to these two population growth models, the growth in Brazil follows the exponential growth model up to 2018 and then it will follow the logistic growth model, whereas the population growths of the other four countries follow the logistic growth model.

The LPB countries are not fully contained within the LPB; therefore, the population models had to be downscaled for the LPB. For each country, the percentage of population that lives in the LPB was determined and the population of the entire basin was determined.

The exponential growth model was used for Brazil, for the part of the country belonging to the LPB, up to the year 2007, and then due to the population size in the basin, the logistic one was used to determine the population in the year 2040, whereas the population growth in the other four countries in the LPB area follows the exponential growth model (Fig. 6). Table 1 shows the prediction for the population in the LPB, as total per country and as population in LPB, every $10 \mathrm{yr}$ from 2010 (collected data from census) till 2040.

\subsection{Total water withdrawal from the LPB}

\subsubsection{Agricultural water withdrawal}

Agricultural water withdrawal (AWW) depends on the water requirements for irrigation, which vary depending on the land use. Moreover, the change in land use over the years is very important in order to determine future agricultural water requirements. While analyzing the land use pattern of the last three decades, 1980-2010, it can be noticed that there is a significant change of cultivation of crops and deforestation (Barros et al., 2008), which result in variations in the annual water demand for agriculture. For each country of the LPB, future water requirements were determined by analyzing the main crops of the countries, such as rice, sunflower, maize, soybean, sorghum, wheat, cassava and sugarcane (Statistical Yearbook for Latin America and 
Table 1. Estimated population in each country of LPB (the total over country and the part located in LPB).

\begin{tabular}{llrrrr}
\hline & & \multicolumn{4}{c}{ Estimated population $\left(10^{6}\right)$} \\
\cline { 3 - 6 } Country & Country & 2010 & 2020 & 2030 & 2040 \\
\hline \multirow{2}{*}{ Argentina } & Total & 40.8 & 44.3 & 47.3 & 49.8 \\
& LPB part & 26.2 & 27.4 & 28.3 & 28.8 \\
Bolivia & Total & 8.8 & 9.4 & 9.8 & 10.2 \\
& LPB part & 1.78 & 2.0 & 2.3 & 2.5 \\
Brazil & Total & 197.2 & 273.7 & 296.2 & 314.6 \\
& LPB part & 84.3 & 94.7 & 105.2 & 115.7 \\
Paraguay & Total & 7.1 & 9.1 & 11.7 & 14.9 \\
& LPB part & 7.1 & 9.1 & 11.7 & 14.9 \\
Uruguay & Total & 3.0 & 3.02 & 3.03 & 3.04 \\
& LPB part & 2.9 & 2.9 & 3.0 & 3.0 \\
\hline \multirow{2}{*}{ Total in LPB } & 122.30 & 136.33 & 150.51 & 165.05 \\
\hline
\end{tabular}

the Caribbean CEPALSTAT, 2009). The average water requirement for each crop is given in Table 2, below. Most of the cultivations in LPB are done using rain water; therefore, irrigation water requirements will be significantly small when compared with the actual water requirement. CEPALSTAT of year 2009 gives the percentages of rainfed and irrigated area per country in LPB (see Table 3), which forms the basis for computing the necessary water withdrawal from the available water in the basin.

The necessary irrigation water requirements (IWR) for each crop were computed and correlated with the present measured agricultural water withdrawal (AWW). Based on this correlation, the future AWW, for each country in LPB was estimated, as per Eq. (9):

$\mathrm{AWW}=a+\sum_{i=1}^{n} b \mathrm{IWRC}_{i 1}+c \mathrm{IWRC}_{i 2}$

where $a, b, c$ are coefficients; IWRC $_{i 1}$ is the irrigation water requirement for a certain crop $i$; IWRC $i 2$ is the crop I water requirement times percentage of the irrigated area; and $n$ is the number of considered crops. Table 4 indicates the total estimated AWW in LPB by country.

\subsubsection{Municipal water withdrawal}

Municipal water withdrawal (MWW) increases with the population growth. Population growth correlated with the historical MWW is used in order to estimate the future MWW in LPB by country (Eq. 10):

$\mathrm{MWW}=(a+b \mathrm{PG})$

where $a, b$ are coefficients and PG is the population growth correlated to the municipal water withdrawal. Table 5 shows the estimated MWW in LPB for each country of the basin.

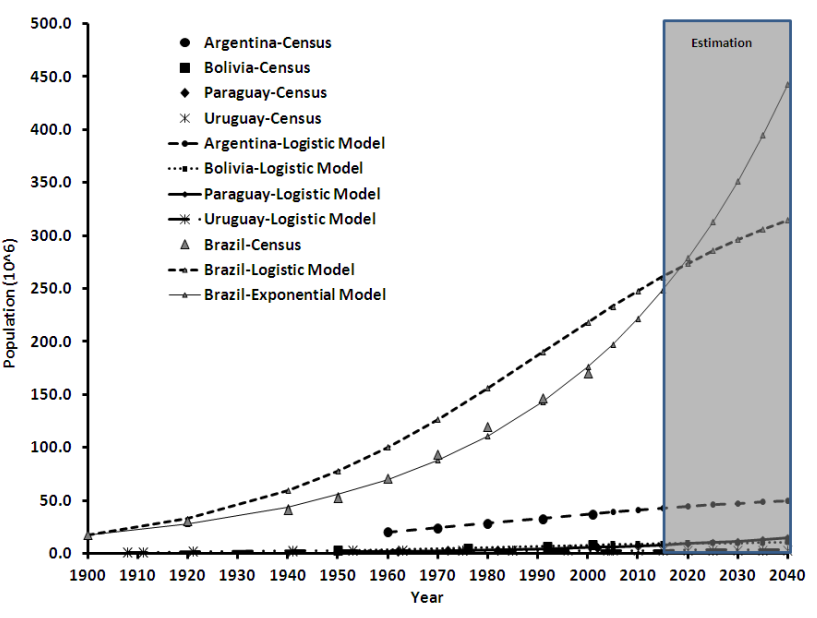

Fig. 6. Growth of population in Argentina, Bolivia, Brazil, Paraguay and Uruguay in LPB.

\subsubsection{Industrial water withdrawal}

Industrial water withdrawal (IWW) depends on factors such as product type, demand for product, rate of production. However, when these types of data are not available, population growth and economic development can be used for assessing future IWW. The IWW is expressed by Eq. (11):

$\mathrm{IWW}=(a+b \mathrm{PG}+c \mathrm{GDP})$

where $a, b, c$ are coefficients; PG is population growth and GDP is the gross domestic product. The estimated IWW for the year 2040 is given in Table 6 .

\subsubsection{Total water withdrawal}

The water withdrawals for each sub-basin of the LPB were computed based on the percentages of basin area shared by each country, and as a sum of the AWW, MWW and IWW.

\subsection{Electricity demand of LPB on 2040}

The electricity demand (ED) of the LPB countries, in the year 2040, is dependent on the population growth and economic development of the region. The consumption of electricity increases with the population growth, and also there is a need for more energy (electricity) for the industrial development, which contributes to the economic development.

Per capita gross domestic product (GDP) was used as an indicator to measure the economic development in each LPB country. The existing GDP product variation in each LPB country was analyzed (Fig. 7), and future GDP was estimated based on the present trend.

The relation that gives the ED for year 2040 is

$\mathrm{ED}=(a+b \mathrm{PG}+c \mathrm{GDP})$

where $a, b, c$ are coefficients, determined from the historical data; PG is the population and GDP is the gross domestic 
Table 2. Average crop water requirements $\left(\mathrm{mm} \mathrm{yr}^{-1}\right)$.

\begin{tabular}{lllllllll}
\hline Description & Rice & Sunflower & Maize & Soybean & Sorghum & Wheat & Cassava & Sugarcane \\
\hline Crop water requirement & $900-2500$ & $600-1000$ & $400-600$ & $450-700$ & $250-300$ & $400-450$ & $1400-3000$ & $400-750$ \\
\hline Source: CEPALSTAT - Statistical Yearbook 2009.
\end{tabular}

Source: CEPALSTAT - Statistical Yearbook 2009

Table 3. Percentages of rainfed and irrigated agricultural areas.

\begin{tabular}{lrrrrr}
\hline Description & $\begin{array}{r}\text { Argentina } \\
(\%)\end{array}$ & $\begin{array}{r}\text { Bolivia } \\
(\%)\end{array}$ & $\begin{array}{r}\text { Brazil } \\
(\%)\end{array}$ & $\begin{array}{r}\text { Uruguay } \\
(\%)\end{array}$ & $\begin{array}{r}\text { Paraguay } \\
(\%)\end{array}$ \\
\hline Rainfed & 92 & 90 & 90 & 97 & 60 \\
Irrigated & 8 & 10 & 10 & 3 & 40 \\
\hline
\end{tabular}

Source: CEPALSTAT - Statistical Yearbook 2009.

Table 4. Estimated agricultural water withdrawal from LPB by country.

\begin{tabular}{lrrrrr}
\hline & \multicolumn{5}{c}{ Agricultural water withdrawal $\left(10^{9} \mathrm{~m}^{3} \mathrm{yr}^{-1}\right)$} \\
\cline { 2 - 6 } Year & Argentina & Bolivia & Brazil & Paraguay & Uruguay \\
\hline 2010 & 16.99 & 0.87 & 31.24 & 0.36 & 3.73 \\
2020 & 20.86 & 0.93 & 36.84 & 0.37 & 4.43 \\
2030 & 24.72 & 0.98 & 42.44 & 0.38 & 5.13 \\
2040 & 28.58 & 1.04 & 48.04 & 0.39 & 5.84 \\
\hline
\end{tabular}

product. The computed ED is plotted in Fig. 8, for all five countries of LPB, up to year 2040.

\subsection{Assessment of the needs of hydropower production in LPB}

In LPB hydropower is one of the foreseen sources for meeting the energy demand (Barros, 2008). Based on the above determined energy demand and analyzing the hydropower production, an estimation of the needs for hydropower production in 2040 has been assessed. The trend of the hydropower production until now (year 2010) and possible needs for hydropower production, based on the current production in each country, is presented in Fig. 9.

\subsection{Determination of hydropower potential of the LPB using VAPIDRO-ASTE tool}

The maximum available hydropower potential of the LPB is determined using the VAPIDRO-ASTE 2.0 GIS integrated tool, as presented earlier in the paper. The VAPIDRO-ASTE tool has the advantage that it encapsulates a methodology to assess the maximum and residual hydropower potential in a watershed at two scales: basin-wide and reach scale. The basin-scale analysis determines the available maximum hydropower potential of a river basin based on the natural available hydrological regime and the topography of the
Table 5. Estimated municipal water withdrawal from LPB by country.

\begin{tabular}{lrrrrr}
\hline & \multicolumn{5}{c}{ Municipal water withdrawal $\left(10^{9} \mathrm{~m}^{3} \mathrm{yr}^{-1}\right)$} \\
\cline { 2 - 6 } Year & Argentina & Bolivia & Brazil & Paraguay & Uruguay \\
\hline 2010 & 3.93 & 0.05 & 5.37 & 0.13 & 0.08 \\
2020 & 4.42 & 0.06 & 5.98 & 0.17 & 0.09 \\
2030 & 4.91 & 0.07 & 6.65 & 0.22 & 0.09 \\
2040 & 5.40 & 0.09 & 7.37 & 0.26 & 0.10 \\
\hline
\end{tabular}

Table 6. Estimated industrial water withdrawal of LPB by country.

\begin{tabular}{rrrrrr}
\hline & \multicolumn{5}{c}{ Industrial water withdrawal $\left(10^{9} \mathrm{~m}^{3} \mathrm{yr}^{-1}\right)$} \\
\cline { 2 - 6 } Year & Argentina & Bolivia & Brazil & Paraguay & Uruguay \\
\hline 2010 & 2.30 & 0.10 & 8.62 & 0.05 & 0.04 \\
2020 & 2.67 & 0.14 & 9.70 & 0.07 & 0.05 \\
2030 & 3.04 & 0.18 & 10.67 & 0.08 & 0.06 \\
2040 & 3.41 & 0.24 & 11.54 & 0.09 & 0.07 \\
\hline
\end{tabular}

catchment, whereas the reach scale does the same analysis at sub-basin level.

The residual hydropower potential expresses the hydropower potential of a basin after taking into account all water withdrawals (AWW, MWW, IWW) and the minimum instream flow (MIF) determined from the natural available hydrological data.

In order to perform the analysis of the LPB hydropower using VAPIDRO-ASTE, the annual mean flow in LPB was taken into consideration. As presented, there is an increased mean annual flow of the streams in LPB after 1970s. Therefore, the maximum hydropower potential was computed, using values for the mean annual flows for the last $30 \mathrm{yr}$ (19702010). By using mean annual flow, a first assumption is made. The inter-annual variability would seem more logical to be used, because there is no unique and linear relationship between water availability and hydropower production (it strongly depends on the rainfall distribution during the year and storage capacity of reservoirs in the basin). However, the intra-annual variability is partially taken into account, because three decades of data were used for the study (mean 1970s to mean 2000s). Moreover, the LPB catchment is very large, and it would not be possible to analyse the entire area, unless such assumptions are made (constant mean discharge over the year). 


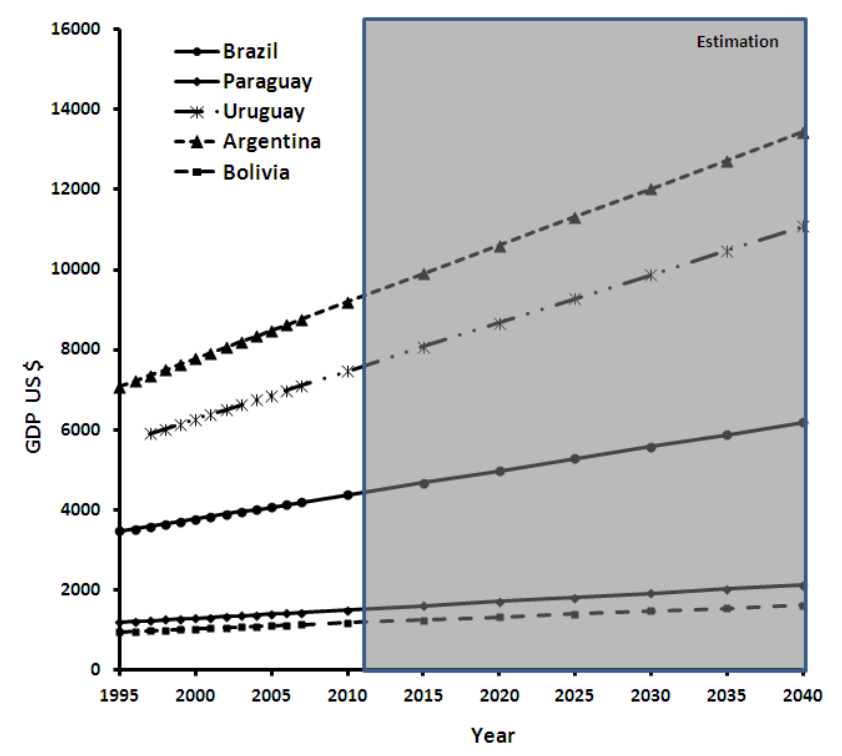

Fig. 7. Variation of per capita gross domestic product (GDP) in five LPB countries.

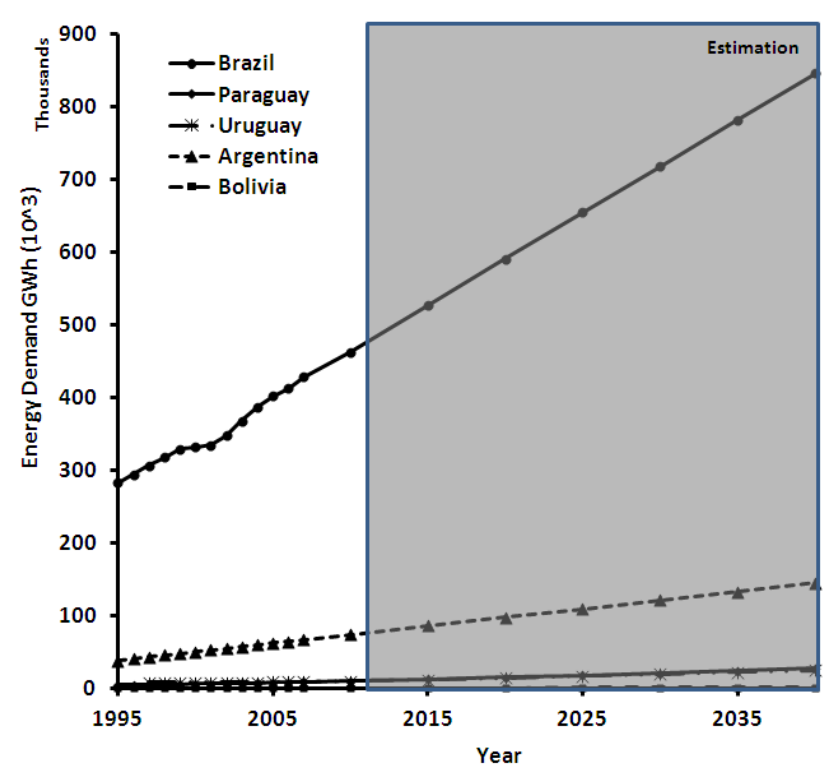

Fig. 8. Actual and estimated electricity demand in five countries in LPB.

Two types of VAPIDRO-ASTE models have been developed: first, models for estimating the maximum hydropower potential, where no withdrawals were considered, were built; and secondly models for estimating the residual hydropower potential, where all future potential water withdrawals from the basin were considered.

The maximum and residual hydropower potential were computed for $0 \%$ and $10 \%$ of the hydrological flow as MIF respectively. The overall efficiency factor for the generation of energy was selected to be $70 \%$ and loss coefficient for the

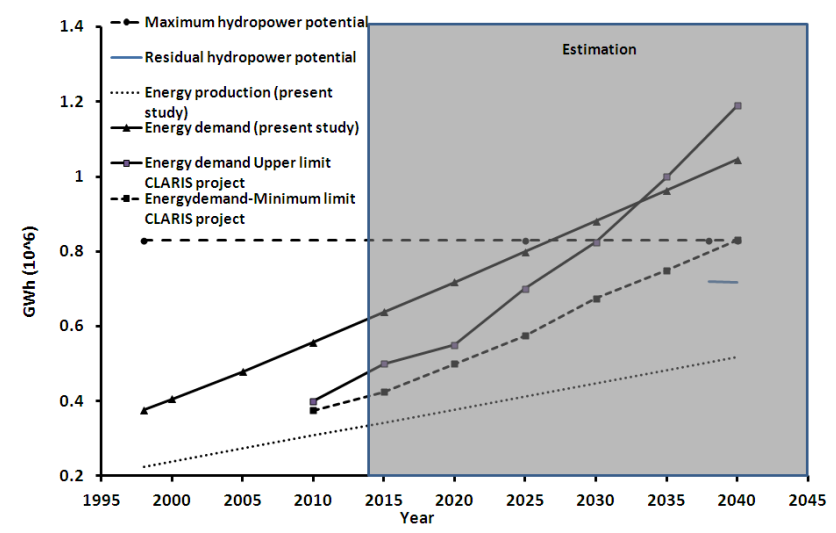

Fig. 9. Potential energy in LPB.

transformation of gross head in net head as 0.05. In case of power generation, hydraulic machine efficiency was selected as $80 \%$ and transmission coefficient between average seasonal maximum discharge and instant discharge was selected as 1.5 .

The LPB was divided into 66 sub-basins, based on measured stream flow data availability. These 66 sub-basins cover the entire LPB taking into account all the main rivers (Paraná, Paraguay, Uruguay, Grande, Tietê, Paranapanema, Ivaí, Iguazu, Parnaíba, Pilcomayo, Bermejo, Negro) and main tributaries. The flow data that determined this division are from the gauging stations located at the outlets that form the sub-basins.

The models main assumption is that there are no diversion structures along the river reaches. The model splits the stream into a number of reaches, delimited by so-called "cross sections" based on the selected distance between two adjacent cross sections. The cross-section points are used to determine what is the head difference of a reach and based on it computes the power and energy available at each cross section. A distance of $50 \mathrm{~m}$ was selected for all the models except for the Paraná, Paraguay and Uruguay main rivers, where distance was selected to be $250 \mathrm{~m}$. The distance of $50 \mathrm{~m}$ was selected based on the topography of the rivers and the availability of stream gauges. VAPIDRO-ASTE has the option to compute the energy and power for the hydraulic head ranging between $0.5 \mathrm{~m}$ and $6 \mathrm{~m}$. This constraint determined that a $50 \mathrm{~m}$ length reach is the space step to be used for the determination of the hydropower potential in the area. The selected 66 sub-basin models calculated power and each cross section considering the back water curve generated by $0.5 \mathrm{~m}$ high hydraulic head.

\section{Results and discussion}

In case that the maximum and residual hydropower potential of the LPB are computed in detail along the river reach, then the obtained values are $354134 \mathrm{GWh}$ and $307034 \mathrm{MWh}$ 
respectively, whereas if they are computed just at the outlet of the sub-basins (i.e. at "basin scale"), these are $829202 \mathrm{GWh}$ and $715602 \mathrm{GWh}$, respectively.

An analysis of the 2040 hydropower production, electricity demand, and maximum and residual hydropower potential together shows to what extent hydropower can contribute to the energy supply in LPB. Figure 9 shows the results obtained in the present research in comparison with the results coming from the EU-FP6 project CLARIS-LAB (www.claris-eu.org), where upper and lower limits for electricity demand in LPB were determined. The analysis shows that the present hydropower production is below the electricity demand of LPB. The gap between residual hydropower potential at basin scale and the hydropower production is the remaining hydropower potential that can be utilized to supply the future electricity demand in LPB. As the electricity demand in LPB on the short term is higher than the maximum hydropower potential at basin scale, hydropower cannot supply the total electricity demand in LPB on the short term. Clearly, there is a need for other sources of energy in order to meet the energy demand of the LPB.

In case of hydropower production and electricity demand, current (year 2010) hydropower production is $309503 \mathrm{GWh}$ and the electricity demand is $557597 \mathrm{GWh}$. Therefore, hydropower contributes $55.5 \%$ of the total electricity demand of LPB. By 2040, the estimated hydropower production and estimated electricity demand will be 523078 and $1045054 \mathrm{GWh}$, respectively, and hydropower will be able to contribute to this demand only with $50.4 \%$ of the total electricity demand. There is a clear need to increase the hydropower production or look into other sources of energy to supply the demand.

Looking at the country level, Paraguay is the only country of the LPB that shows more hydropower production than the electricity demand. In the other four countries, electricity demand is higher than the hydropower production. Therefore, the excess hydropower of Paraguay can be used to supply the electricity demand in other countries, for example Brazil, as it is already the case.

\section{Conclusions}

There is a worldwide concern to get the maximum use of renewable sources, especially hydropower, to supply the increasing energy demand. In this regard, in order to predict the energy demand and availability for the expected future socio-economic developments of the five fast growing countries sharing La Plata Basin, we used a GIS-based tool to assess maximum and residual hydropower potential in the basin, taking into account energy losses, due to different water withdrawals.

In details, this study assessed the present hydropower production and electricity demand generated over the last 20 years in La Plata Basin; estimated the water withdrawals due to industrial, agricultural and municipal uses; estimated the maximum hydropower potential in the basin and computed the residual hydropower potential, accounting for the water withdrawals.

The main outcomes of this study can be summarized in that there is unexploited hydropower potential in LPB, and therefore the remaining hydropower potential of the basin can be utilised to supply the electricity demand in LPB.

The level of representation of the river reaches in the GIS environment is indeed crucial to estimate the hydropower potential: in the work presented in this study, levels of tributaries up to 12 were exploited for hydropower potential assessment, while a previous study, based on 5 levels of tributaries (without taking into account water withdrawals in the basin), estimated a lower potentiality for the basin (Palomino Cuya et al., 2013).

The present study shows that LPB has more hydropower potential than the estimated maximum and residual hydropower potential, because the study considered just 66 streams of LPB for the assessment of the maximum and residual hydropower potential (at river reach scale). However, there are many unaccounted streams for the assessment of hydropower potential of the basin, which can be used for the hydropower generation on a small scale. When considering smaller areas, however, often data availability is scanty at gauge level and the analysis should be done at least using the discharge duration curve and the analysis for ungauged catchments (Castellarin et al., 2007; Vogel and Fennessey, 1995).

This study made several assumptions that need to be addressed in future analysis, which will not only look at a denser catchment representation of the LPB but also at the uncertainties that are associated with the main assumptions made while conducting this study, such as population growth, energy consumption, rainfall distribution, possibilities of having the agricultural water withdrawals in the upstream of the catchment, partially returned at a downstream location. Next study should also consider the sensitivity analysis on the numerical parameters of VAPIDRO-ASTE, such as length of the space discretisation and head associated with this discretisation.

Acknowledgements. Part of the streamflow and geophysical data used for this research was kindly provided by CLARIS LPB EU project of the FP7 R\&D EU Programme [www.claris-eu.org].

Edited by: E. Toth 


\section{References}

Alexandersson, H.: A homogeneity test applied to precipitation data, J. Climatol., 6, 661-675, 1986.

Alterach, J., Peviani, M., Davitti, A., Vergata, M., and Elli, A.: A GIS integrated tool to evaluate the residual potential hydropower production at watercourse scale. Proceedings of the 13th International Water Resources Association, Montpellier, France, September, 2008.

Barros, V., Clarke, R., and Silva Dias, P.: Climate change in the La Plata Basin, SGA II 057, Inter American Institute on Global Change (IAI), Buenous Aires, 44-54, 104-115, 2008.

Bartle, A.: Hydropower potential and development activities, Energy Policy, 30, 1231-1239, doi:10.1016/s0301-4215(02)000848, 2002.

Buishand, T. A.: Some methods for testing the homogeneity of rainfall records, J. Hydrol., 58, 11-27, 1982.

Carlson, T.: Über Geschwindigkeit und Grösse der Hefevermehrung in Würze, Biochem. Z., 57, 313-334, 1913.

Castellarin, A., Camorani, G., and Brath, A.: Predicting annual and long-term flowduration curves in ungauged basins, Adv. Water Resour., 30, 937-953, 2007.

CEPALSTAT - Statistical Yearbook for Latin America and the Carribbean, available at: http://website.eclas.cl/anuario_estadictico/ anuario_2010/eng/index.asp (last access: 2011), 2009.

Chang, X., Liu, X., and Zhou, W.: Hydropower in China at present and its further development, Energ. Policy, 35, 4400-4406, 2010.

Clarke, R. T.: Hydrological prediction in a non-stationary world, Hydrol. Earth Syst. Sci., 11, 408-414, doi:10.5194/hess-11-4082007, 2007.

Collischonn, W., Tucci, C., and Clark, R.: Further evidence of changes in the Hydrology regime of the Paraguay River, J. Hydrol., 245, 218-238, 2001.

Conolly, D., Lund, H., Mathiessen, B. V., and Leahy, M.: A review of computer tools for analyzing the integration of renewable energy into various energy systems, Appl. Energ., 87, 1059-1082, 2010.

Dudhani, S., Sinha, A. K., and Inamdar, S. S.: Assessment of small hydropower potential using remote sensing data for sustainable development in India, Energ. Policy, 34, 3195-3205, 2006.

FAOSTAT: Data base (Aquastat), Food and Agricultural Organization of the United Nations (FAO), available at: http://www. fao.org/nr/water/aquastat/dbase/index.stm, last access: December 2011 .

Gichamo, T. Z., Popescu, I., Jonoski, A., and Solomatine, D.: River cross-section extraction from the ASTER global DEM for flood modeling, Environ. Modell. Softw., 31, 37-46, doi:10.1016/j.envsoft.2011.12.003, 2012.

Hartanto, I. M., Beevers, L., Popescu, I., and Wright, N. G.: Application of a coastal modelling code in fluvial environments, Environ. Modell. Softw., 26, 1685-1695, doi:10.1016/j.envsoft.2011.05.014, 2011.
Hawkins, M.: Testing a sequence of observations for a shift in location, J. Am. Stat. Assoc., 72, 180-186, 1977.

IHA/IEA/CHA: Hydropower and the World's Energy Future, White Paper published by the International Hydropower Association, the International Energy Agency-Implementing Agreementon Hydropower, and the Canadian Hydropower Association, November, 2000.

INDEC - National Institute of Statistics and Censuses Argentina: www.indec.mecon.ar/indec/ingles.asp, last access: December 2011.

Kosnik, L.: The potential of water power in the fight against global warming in the US, Energ. Policy, 36, 3252-3265, 2008.

Kosnik, L.: The potential of water power in the fight against global warming in the US, Energ. Policy, 38, 5512-5519, 2010.

Mondal, M. A. H. and Denich, M.: Assessment of renewable energy resources potential for electricity generation in Bangladesh, Renewable and Sustainable Energy Reviews, 14, 2401-2413, 2011.

Ohunakin, O. S., Ojolo, S. J., and Ajayi, O. O.: Small hydropower (SHP) development in Nigeria: An assessment, Renewable and Sustainable Energy Reviews, 15, 2006-2013, 2011.

Organisation of American States (OSA), La Plata basin: A framework for the sustainable management of its water resources with respect to the hydrological effects of climate variability and change, Organization of American States, Water project series, October, 2005.

Palomino Cuya, D. G., Brandimarte, L., Popescu, I., Alterach, J., and Peviani, M.: A GIS-based assessment of maximum potential hydropower production in La Plata basin under global changes, Renew. Energ., 50, 103-114, doi:10.1016/j.renene.2012.06.019, 2013.

Pettitt, A. N.: A non-parametric approach to the change-point detection, Appl. Stat., 28, 126-135, 1979.

Qurios, R.: The La Plata river basin development and riverine fisheries, LARS, The Second International symposium on the Management of Large Rivers for Fisheries, Phnom Penh, Kingdom of Cambodia, February 2003, http://www.agro.uba.ar/ users/acuatica/LaPlata/LAPLATABASINFISHERIES.PDF (last access: December 2011), 5-9, 2002.

Supriyasilp, T., Pongput, K., and Boonyasirikul, T.: Hydropower development priority using MCDM method, Energ. Policy, 37, 1866-1875, 2009.

Vogel, R. M. and Fennessey, N. M.: Flow Duration Curves Ii: a Review of Applications in Water Resources Planning, J. American Water Resour. As., 31, 1029-1039, 1995.

WWAP-UNESCO: UN-water/WWAP/2007/1, La Plata Basin Case Study, Final Report, World Water Assessment programme, United Nations Educational, Scientific and Cultural Organization, March 2007, 1-6, 242-259, available at: http://unesdoc. unesco.org/images/0015/001512/151252e.pdf (last access: December 2011), 2007.

Yuksel, I.: As a renewable energy hydropower for sustainable development in Turkey, Sustain. Energy Rev., 14, 3213-3219, 2010. 